\title{
Regulation of Collagen Synthesis in Tobacco/Pan-Masala Induced Oral Sub- Mucosal Fibrosis and Diagnostic Approach - Review Article
}

\author{
Shraddha Awasthi ${ }^{1 *}$, Ausaf Ahmad ${ }^{2}$, Anand Narain Srivastava ${ }^{1}$ \\ ${ }^{1}$ Department of Pathology, ERA University, Sarfarazganj, Hardoi Road, Lucknow, Uttar Pradesh, India \\ ${ }^{2}$ Amity Institute of Biotechnology, Amity University Uttar Pradesh, Lucknow, Uttar Pradesh, India \\ *Corresponding Author Email ID: shraddhar72@gmail.com
}

\begin{abstract}
Article Info

Volume 8, Issue 1

Page Number: 134-143

Publication Issue :

January-February-2021

\section{Article History}

Accepted : 01 Jan 2021

Published : 06 Jan 2021

Introduction : oral submucosal fibrosis (OSMF) is related to juxta epithelial inflammatory response followed by a fibroelastic change of the lamina propria, with epithelial atrophy leading to stiffness of the oral mucosa, causing trismus and inability to eat.

Methods and Materials: The suitability standards for studies were: Research Articles that studied the metabolic activities in oral submucous fibrosis mainly caused by some carcinogenic substances or chemicals which may present in tobacco, alcohol, cigarettes, pan-masala etc Reference list of selected articles and reviews on the topic also were searched. studies were extracted, A total of 90-100 studies were extracted, using the keywords oral submucous fibrosis, oral potentially malignant lesion and diagnosis, collagen synthesis etc.,

Results: cancer risk among these patients, periodic biopsies of suspicious regions of the oral mucosa are essential for the early detection and management of high-risk oral premalignant lesions and prevention of cancer.

Conclusion: OSMF is hardly recognized and is poorly understood across the globe. significant improvement in management, nor reduction in its high malignant transformation rate. Better integration of medical and dental services, especially in developing countries, may reduce patients' suffering and improve their life quality.

Keywords : Oral Sub-Mucosal Fibrosis, Oral Potentially Malignant Lesion Diagnosis, Collagen Synthesis.
\end{abstract}

\section{INTRODUCTION}

Oral submucous fibrosis (OSMF) is a deceptive longlasting disease affecting slightly part of the oral cavity and sometimes the pharynx. Even though infrequently preceded by and or related with construction of vesicles, it is always associated with juxta epithelial inflammatory reaction of oral mucosa followed by a fibroelastic change of the lamina propria, with epithelial atrophy leading to stiffness of the oral mucosa, causing trismus and inability to eat [1]. OSMF has a high rate of indisposition because it causes progressive incapability to open the mouth, resulting in inability to eat and consequent 
nutritional deficiencies [2]. Mortality rate is significant because it alters into oral cancer, particularly squamous cell carcinoma at a rate of $7 \%-$ 30\% [3] Management includes termination of habit and surgical release of fibrous bands followed by forceful opening of the mouth by coronoid ectomy and treatment of surgical defects with nasolabial flap and post-operative active jaw physiotherapy for 6 months [3]. The strongest risk issue for OSMF is that the change of state of betel quid containing edible seed. OSMF is seen most commonly in community's resident in the Indian sub-continent and has a reported incidence of between $0.2-1.2$ percent of the urban population attending dental clinics. The illness predominantly affects women with a female: male ratio of 3:1 and characteristically first presents in adulthood between the ages of $45-54$ years (8). The possibly malignant nature of this condition has been well documented. A malignant transformation rate of $4.5 \%$ to $7.6 \%$ was found (9). The reports appraise the malignant potential of oral sub mucous fibrosis. Appearance wasn't seen, suggesting loss of cheek elasticity. A diagnosis of OSMF at a moderately advanced stage was made based on the characteristic oral features: widespread blanching of buccal mucosa, extensive fibrosis and limited mouth opening. In addition to the above changes, an ulcero-proliferative growth (measuring about $3 \times 2 \mathrm{~cm}$ ) was present on the right buccal mucosa extending from the corner of mouth to the molar area showing asymmetrical and indurated margins. It was stable in consistency and fixed to underlying tissue. The sub-mandibular and jugulodigastric lymph nodes were palpable. The current review presents OSMF from a molecular outlook and evaluations what is known aspects about its fundamental mechanisms, diagnostic biomarkers, and therapeutic involvements. Moreover, to the destructive treatment of OSMF, its anticipation is also important. Future research should, therefore, focus on improving the oral health literacy of the patients susceptible to OSMF.

\section{METHODS AND MATERIALS}

The suitability standards for studies were: Research Articles that studied the metabolic activities in oral submucous fibrosis mainly caused by some carcinogenic substances or chemicals which may present in tobacco, alcohol, cigarettes, pan-masala etc. The reference list of selected articles and reviews on the topic also were searched. A total of 90-100 studies were extracted, using the keywords oral submucous fibrosis, oral potentially malignant lesion and diagnosis, collagen synthesis etc.

\section{Clinical features}

The sign and symptoms of OSMF due to inflammatory response and, primarily, fibrosis. the foremost common initial symptoms and signs are burning sensation, dry mouth, blanching oral mucous membrane, and ulceration. The burning sensation sometimes happens whereas mastication happens by spicy food.[69] Blanching of the oral mucous membrane is caused by impairment of native property attributable to increasing pathology and ends up in a look like marble.[70] Blanching could also be localized, diffuse, or crisscross. In some cases, blanching could also be related to small vesicles that rupture to make erosions. Patients complain that these vesicles type once they eat spicy food. These options are often ascertained in the least stages of OSMF. within the additional advanced stage of the unwellness, the essential feature may be a fibrous band limiting mouth gap and inflicting issue in manuduction, speech, swallowing, and maintaining oral hygiene [71]. Development of fibrous bands within the lip makes the lip thick, rubbery, associated troublesome to retract or evert; a band round the lips offers the mouth gap an elliptical form. pathology makes cheeks thick and rigid. once a patient blows a whistle or tries to inflate a balloon, the same old puffed out look of the cheeks is missing. within the 
tongue, depapillation of the mucous membrane round the tip and lateral margins might occur with blanching or pathology of the ventral mucous membrane. pathology of the tongue and therefore the floor of the mouth interfere with tongue movement. surface involvement includes extensively blanched mucous membrane. pathology might extend posteriorly to involve the taste bud and flap. The latter might seem shrunken and, in extreme cases, budlike. animal tissue involvement is comparatively uncommon and is characterised by pathology, blanching, and loss of traditional stippling. In rare cases of intensive involvement, there could also be loss of hearing due to blockage of tubes and issue in swallowing attributable to muscular structure pathology.[72] numerous classifications are purposed betting on the clinical options like by Wahi et al. [73] (1966) World Health Organization classified OSMF on the idea of clinical options, severity, and extent of involvement into 3 clinical groups; another classification was by Sirsat and Pindborg (1967) [74] World Health Organization classified the microscopic anatomy image of OSMF into four stages. Lai et al. [75] classified patients on the idea of mouth gap. we've staged our patients as per the classification of Lai et al.

\section{Pathological Symptoms and Molecular Mechanism.}

Pathological Signs Chewing betel nut and consumption of tobacco components is the basic cause of OSMF [21-24]. The histopathology of OSMF incorporates numerous epithelial alterations, rete-peg shapes, and subepithelial deposition of dense bands of collagen fibres. At different OSMF stages, epithelial alterations differ and degenerate with hypoplasia to hyperplasia and/or dysplasia [25,26]. A change in epithelial acquiescence in response to enhanced connective tissue fibrosis favours the beginning of carcinomatous developments like epithelialmesenchymal transition (EMT) [27,28]. The most common preliminary symptoms of OSMF are ulceration, xerostomia, a burning sensation, and limited capability to open the mouth $[29,30]$. These effects restrict the daily life of the patient and may lead to complications. After tissue damage, myofibroblasts differentiate into contractile and secretory cells to close the lesions, produce compounds of the extracellular matrix (ECM) and secrete cytokines. However, unnecessary growth of ECM proteins such as collagen may result in pathological fibrosis.

\section{Defective Collagen Homeostasis}

Numerous studies confirmed that OSMF is the consequence of collagen dysregulation, namely, increased biosynthesis and reduced clearance $[31,32,33]$. Tobacco and its constituents contribute to these alterations in collagen metabolism. Betel nut encompasses alkaloids, flavonoids, and copper. All of these affects with ECM homeostasis in oral tissue [34]. A high amount of betel nut chewers also smokes tobacco and drink alcohol. Studies confirmed that tobacco smoking and alcohol consumption have an additive effect on OSF pathogenesis [35].

\section{Increased Collagen Synthesis}

The four main alkaloids in edible seed area unit arecoline, arecaidine, guvacine, and guvacoline. These increases fibroblasts to produce collagen $[36,37,38]$. Both OSMF- and normal cells produce $\sim 85 \%$ type I collagen and $\sim 15 \%$ type III collagen. In OSMF cells, however, the ratio of the $\alpha 1$ (I) to $\alpha 2$ (I) chains of type I collagen is $\sim 3: 1$ whereas in normal cells it is 2:1 $[39,40]$. Moreover, the addition of slaked lime calcium hydroxide) to betel nut in pan facilitates the chemical reaction of arecoline to arecaidine. The latter amplifies fibroblastic proliferation and increase collagen formation.

\section{Reduced Collagen Clearance}

Collagen clearance is compact by collagen stability, defective extracellular matrix dynamics, and 
inhibition of activity. Arecoline encourages the development of cross-links between amide collagen chains that reduces the collagen proof against degradation by collagenases [41,42]. The active components in areca nut encourage substantial amounts of collagen synthesis within the oral membrane cells. Cystatin C inhibits amino alkanoic acid proteinases and may additionally stabilize collagen fibres in OSMF [43]. Formative cell activity plays a vital role within the regulation of ECM remodelling by collagen degradation [45]. However, fibroblasts from patients with OSMF square measure markedly deficient in collagen activity. This defect could lead to pathology $[46,47]$. it had been in contestable that collagen activity was pent-up in OSMF fibroblasts treated with arecoline $[48,49]$. Flavonoids like tannins and catechins square measure different vital parts of areca nut and work synergistically with alkaloids to induce OSMF. Flavonoids stabilize collagen by inhibiting enzyme and helpful collagen fibrous bands [50]. Localized membrane inflammation elicited by areca nut recruits activated $\mathrm{T}$ cells and macrophages and will increase cytokines and TGF- $\beta$. TGF- $\beta$ considerably will increase collagen production by activating the procollagen genes COL1A2, COL3A1, COL6A1, COL6A3, and COL7A1. It conjointly will increase procollagen enzyme and upregulates lysyl enzyme (LOX) that cross-links collagen fibers $[51,52]$. TGF- $\beta$ conjointly impedes collagen degradation by activating the tissue substance of the matrix metalloproteinase (TIMP) cistron and therefore the proteinase substance (PAI) [53,54]. diminished levels of gelatinolytic proteinase like MMP (matrix metalloproteinase)-2 and MMP-9 secreted by fibroblasts and accumulated levels of TIMP-1 contribute to the loss of ECM equilibrium in OSF $[55,56]$.

\section{Inflammatory Cytokines and Growth Factors}

During betel nut chewing, the thick fibres injure the oral mucosa which causes inflammation of epidermal cells and stimulates macrophages to secrete cytokines. Transforming growth factor- $\beta$ (TGF- $\beta$ ) is a main cytokine involved in OSMF progression. It controls the presence of $\alpha$-SMA and type 1 collagen in myofibroblasts $[57,58]$. Studies have shown arecoline made connective tissue growth factor (CTGF) biosynthesis via reactive oxygen species (ROS) and the NF-kB, JNK, and p38 MAPK pathways in buccal mucosal fibroblasts $[59,60]$. CTGF overexpression in individuals with the betel nut chewing habit may improve fibrotic activity and pathogenesis in OSMF $[61,62]$. Arecoline also upregulates other proinflammatory and profibrotic cytokines such as IL-1, IL-6, IL-8, TNF- $\alpha$, PDGF, b-FGF, and KGF-1. It downregulates IFN- $\gamma$ which, in turn, encourages collagen synthesis $[63,64]$. Variations in cytokines and growth factors cause fibroblast proliferation and collagen synthesis near the site of injury, thereby resulting in fibrosis $[65,67]$. In addition to the classic targets of fibrosis-TGF- $\beta$, IL- 6 and more-a large amount of confirmation from across various tissues, such as heart, lung, skin, liver, colon, and kidney, indicated that IL-17 and its downstream pathways are closely related to the initiation and proliferation of fibrosis [68]. The role of IL-17 in the progression of OSF has not yet been explored, and this subject is worthy to investigate in the future.

\section{Diagnostic Approach}

Diagnosis of OSMF is based on clinical signs and symptoms that may contain burning sensation in mouth, pain, and ulceration [10,11,12]. Progressive restriction in proper mouth opening, blanching of the mucosa, depapillation of the tongue, and loss of pigmentation are other classic features $[13,14]$. Inability to eat and hearing impairment is also observed in advanced cases [15, 16]. Quality of life is harshly affected, deteriorating with increasing every stage of the disease [17]. OSMF progresses over time and management depends on the stage at clinical sign and clinical presentation sometimes on the basis of 
patient's history or background. In 2012, More et al. proposed a disease progression-based classification which characterizes the clinical and functional staging of OSMF. This classification has been widely accepted/ recommended as the closest fit for Indian population, especially to understand the disease progression/ clinical pattern $[18,19,20]$. In 2017, Passi D. et al. proposed a pathologically updated and treatment management-based classification.

\section{Treatment}

No well-known treatment for OSMF is effective, though some conservative and surgical interventions might surgical improvement. most vital aspect of medical treatment is that the cessation of habit of ingestion betel pepper quid, areca nut, alternative local irritants, spicy and hot food, alcohol, and smoking. the most common mode of medical treatment had been the utilization of steroids in its numerous forms. different ways represent injection of placental extract, use of enzyme, and intralesional antiviral interferons (IFN $\gamma$ ). [76,77] Oral metallic element likewise as oral pentoxiphylline [78] and carotenoid are used with varied advantages. Despite abundant progress in understanding the pathological process and treatment of OSMF within the absence of properly designed trials and lack of standardized doses and length of treatment, we tend to had standardized and counselled the treatment in our cases. The list of treatment modalities is in depth and includes the utilization of micronutrients and minerals, $\mathrm{CO} 2$ laser, Trental, lycopene, antiviral gamma, turmeric, hyalase, chymotrypsin, and placental extracts. As pathology cannot be reversed once mouth gap is severely reduced, surgical interventions like surgery, coronoidectomy, and excision of fibrotic bands have additionally been according in literature. as an alternative, procedures like insertion of tubing, therapy, native heat medical aid, and mouth gap exercises with acrylic carrots and ice cream sticks are tried with variable success rates. Kakar et al. according that patients treated with proteins showed faster improvement in symptoms however a mix of corticosteroids gave higher and future results.[79] Steroids square measure documented immunological disorder agents for suppression of fibro productive inflammation found in OSMF. Protein degrades the fibrous matrix promoting the lysis of protein chunk and activating specific plasmatic mechanism. Relief of symptoms of stiffness in mouth happens through softening and decreasing animal tissue. [80,81,82] within the on top of according cases intralesional steroid injection with injection protein was given once every week to create the treatment value effective and for higher patient compliance. The patients showed relief of symptoms of burning sensation, hypersensitivity to spicy food, and oral ulceration at the side of a subjective sense of reduced stiffness in buccal membrane once administration of injections biweekly for two months.

\section{CONCLUSION}

The cases explain the significant morbidity and mortality associated with OSMF and emphasize the importance of close follow-up of such cases. Because of the significant cancer risk among these patients, periodic biopsies of suspicious regions of the oral mucosa are essential for the early detection and management of high-risk oral premalignant lesions and prevention of cancer. Although studied intensively over many decades, one might say centuries, especially in South Asia, OSMF is hardly recognized and is poorly understood across the globe. significant improvement in management, nor reduction in its high malignant transformation rate. Improved incorporation of medical and dental services, especially in developing countries, may reduce patients' suffering and improve their life quality. All health care professions must work together in public education and primary prevention. 


\section{REFERENCES}

[1]. Pillai R, Balaram P, Reddiar KS. Pathogenesis of oral submucous fibrosis: relationship to risk factors associated with oral cancer. Cancer. 1992;69(8):2011-2020

[2]. Shevale VV, Kalra RD. Management of oral submucous fibrosis: a review. Indian Journal of Dental Sciences. 2012;4(2).

[3]. Borle RM, Nimonkar PV, Rajan R. Extended nasolabial flaps in the management of oral submucous fibrosis. British Journal of Oral and Maxillofacial Surgery. 2009.

[4]. Dijkstra PU, Sterken MW, Pater R, Spijkervet FKL, Roodenburg JLN. Exercise therapy for trismus in head and neck cancer. Oral Oncology. 2007;43(4):389-394.

[5]. Le PV, Gornitsky M. Oral stent as treatment adjunct for oral submucous fibrosis. Oral Surgery, Oral Medicine, Oral Pathology, Oral Radiology, and Endodontics. 1996.

[6]. Stubblefield MD, Manfield L, Riedel ER. A preliminary report on the efficacy of a dynamic jaw opening device (dynasplint trismus system) as part of the multimodal treatment of trismus in patients with head and neck cancer. Archives of Physical Medicine and Rehabilitation. 2010.

[7]. Le PV, Gornitsky M. Oral stent as treatment adjunct for oral submucous fibrosis. Oral Surgery, Oral Medicine, Oral Pathology, Oral Radiology, and Endodontics. 1996.

[8]. Stubblefield MD, Manfield L, Riedel ER. A preliminary report on the efficacy of a dynamic jaw opening device (dynasplint trismus system) as part of the multimodal treatment of trismus in patients with head and neck cancer. Archives of Physical Medicine and Rehabilitation. 2010;91(8):1278-1282.

[9]. Hazarey VK, Erlewad DM, Mundhe KA, Ughade SN. Oral submucous fibrosis: study of
1000 cases from central India. Journal of Oral Pathology and Medicine. 2007;36(1):12-17.

[10]. Zhang X., Reichart P.A. A review of betel quid chewing, oral cancer and precancer in Mainland China. Oral Oncol. 2007;43:424-430.

[11]. Rajalalitha P., Vali S. Molecular pathogenesis of oral submucous fibrosis-A collagen metabolic disorder. J. Oral Pathol. Med. 2005;34:321-328.

[12]. Pant I., Kumar N., Khan I., Rao S.G., Kondaiah P. Role of areca Nut induced TGF-beta and epithelial-mesenchymal interaction in the pathogenesis of oral submucous fibrosis. PLoS ONE. 2015;10:e0129252.

[13]. Rajalalitha P., Vali S. Molecular pathogenesis of oral submucous fibrosis-A collagen metabolic disorder. J. Oral Pathol. Med. 2005;34:321-328.

[14]. Lin C.Y., Hsieh P.L., Liao Y.W., Peng C.Y., Yu C.C., Lu M.Y. Arctigenin reduces myofibroblast activities in oral submucous fibrosis by LINC00974 inhibition. Int. J. Mol. Sci. 2019;20:1328.

[15]. Yeh M.C., Chen K.K., Chiang M.H., Chen C.H., Chen P.H., Lee H.E., Wang Y.H. Low-power laser irradiation inhibits arecoline-induced fibrosis: An in vitro study. Int. J. Oral Sci. 2017;9:38-42.

[16]. Haque M.F., Harris M., Meghji S., Barrett A.W. Immunolocalization of cytokines and growth factors in oral submucous fibrosis. Cytokine. 1998;10:713-719.

[17]. Wang Y.Y., Tail Y.H., Wang W.C., Chen C.Y., Kao Y.H., Chen Y.K., Chen C.H. Malignant transformation in 5071 southern Taiwanese patients with potentially malignant oral mucosal disorders. BMC Oral Health. 2014;14:99.

[18]. Angadi P.V., Rao S.S. Areca nut in pathogenesis of oral submucous fibrosis: Revisited. Oral Maxillofac. Surg. 2011;15:1-9.

[19]. Jeng J.H., Ho Y.S., Chan C.P., Wang Y.J., Hahn L.J., Lei D., Hsu C.C., Chang M.C. Areca nut 
extract up-regulates prostaglandin production, cyclooxygenase-2 mRNA and protein expression of human oral keratinocytes. Carcinogenesis. 2000;21:1365-1370.

[20]. Aziz S.R. Oral submucous fibrosis: Case report and review of diagnosis and treatment. J. Oral Maxillofac. Surg. 2008;66:2386-2389.

[21]. Pindborg J.J., Sirsat S.M. Oral submucous fibrosis. Oral Surg. Oral Med. Oral Pathol. 1966;22:764-779.]

[22]. Fang C.Y., Hsia S.M., Hsieh P.L., Liao Y.W., Peng C.Y., Wu C.Z., Lin K.C., Tsai L.L., Yu C.C. Slug mediates myofibroblastic differentiation to promote fibrogenesis in buccal mucosa. J. Cell. Physiol. 2019;234:6721-6730.

[23]. Speight P.M., Khurram S.A., Kujan O. Oral potentially malignant disorders: Risk of progression to malignancy. Oral Surg. Oral Med. Oral Pathol Oral Radiol. 2018;125:612627.

[24]. Das R.K., Anura A., Pal M., Bag S., Majumdar S., Barui A., Chakraborty C., Ray A.K., Sengupta S., Paul R.R., et al. Epithelio-mesenchymal transitional attributes in oral sub-mucous fibrosis. Exp. Mol. Pathol. 2013;95:259-269.

[25]. Muthu Rama Krishnan M., Pal M., Bomminayuni S.K., Chakraborty C., Paul R.R., Chatterjee J., Ray A.K. Automated classification of cells in sub-epithelial connective tissue of oral sub-mucous fibrosis-an SVM based approach. Comput. Biol. Med. 2009;39:10961104.

[26]. Leight J.L., Wozniak M.A., Chen S., Lynch M.L., Chen C.S. Matrix rigidity regulates a switch between TGF-beta1-induced apoptosis and epithelial-mesenchymal transition. Mol. Biol. Cell. 2012;23:781-791.

[27]. Gjorevski N., Boghaert E., Nelson C.M. Regulation of epithelial-mesenchymal transition by transmission of mechanical stress through epithelial tissues. Cancer Microenviron. 2012;5:29-38.

[28]. Fang C.Y., Hsia S.M., Hsieh P.L., Liao Y.W., Peng C.Y., Wu C.Z., Lin K.C., Tsai L.L., Yu C.C. Slug mediates myofibroblastic differentiation to promote fibrogenesis in buccal mucosa. J. Cell. Physiol. 2019;234:6721-6730.

[29]. Angadi P.V., Rekha K.P. Oral submucous fibrosis: A clinicopathologic review of 205 cases in Indians. Oral Maxillofac. Surg. 2011;15:1519.

[30]. Aziz S.R. Oral submucous fibrosis: Case report and review of diagnosis and treatment. J. Oral Maxillofac. Surg. 2008;66:2386-2389.

[31]. Speight P.M., Khurram S.A., Kujan O. Oral potentially malignant disorders: Risk of progression to malignancy. Oral Surg. Oral Med. Oral Pathol Oral Radiol. 2018;125:612627.

[32]. Das R.K., Anura A., Pal M., Bag S., Majumdar S., Barui A., Chakraborty C., Ray A.K., Sengupta S., Paul R.R., et al. Epithelio-mesenchymal transitional attributes in oral sub-mucous fibrosis. Exp. Mol. Pathol. 2013;95:259-269.

[33]. Muthu Rama Krishnan M., Pal M., Bomminayuni S.K., Chakraborty C., Paul R.R., Chatterjee J., Ray A.K. Automated classification of cells in sub-epithelial connective tissue of oral sub-mucous fibrosis-an SVM based approach. Comput. Biol. Med. 2009;39:10961104.

[34]. Leight J.L., Wozniak M.A., Chen S., Lynch M.L., Chen C.S. Matrix rigidity regulates a switch between TGF-beta1-induced apoptosis and epithelial-mesenchymal transition. Mol. Biol. Cell. 2012;23:781-791.

[35]. Gjorevski N., Boghaert E., Nelson C.M. Regulation of epithelial-mesenchymal transition by transmission of mechanical stress through epithelial tissues. Cancer Microenviron. 2012;5:29-38. 
[36]. Fang C.Y., Hsia S.M., Hsieh P.L., Liao Y.W., Peng C.Y., Wu C.Z., Lin K.C., Tsai L.L., Yu C.C. Slug mediates myofibroblastic differentiation to promote fibrogenesis in buccal mucosa. J. Cell. Physiol. 2019;234:6721-6730.

[37]. Angadi P.V., Rekha K.P. Oral submucous fibrosis: A clinicopathologic review of 205 cases in Indians. Oral Maxillofac. Surg. 2011;15:1519.

[38]. Arakeri G., Rai K.K., Hunasgi S., Merkx M.A.W., Gao S., Brennan P.A. Oral submucous fibrosis: An update on current theories of pathogenesis. J. Oral Pathol. Med. 2017;46:406412.

[39]. Aziz S.R. Oral submucous fibrosis: Case report and review of diagnosis and treatment. J. Oral Maxillofac. Surg. 2008;66:2386-2389.

[40]. Arakeri G., Brennan P.A. Oral submucous fibrosis: An overview of the aetiology, pathogenesis, classification, and principles of management. Br. J. Oral Maxillofac. Surg. 2013;51:587-593.

[41]. Arakeri G., Rai K.K., Hunasgi S., Merkx M.A.W., Gao S., Brennan P.A. Oral submucous fibrosis: An update on current theories of pathogenesis. J. Oral Pathol. Med. 2017;46:406412.

[42]. Aziz S.R. Oral submucous fibrosis: Case report and review of diagnosis and treatment. J. Oral Maxillofac. Surg. 2008;66:2386-2389.

[43]. Arakeri G., Rai K.K., Hunasgi S., Merkx M.A.W., Gao S., Brennan P.A. Oral submucous fibrosis: An update on current theories of pathogenesis. J. Oral Pathol. Med. 2017;46:406412.

[44]. Tilakaratne W.M., Klinikowski M.F., Saku T., Peters T.J., Warnakulasuriya S. Oral submucous fibrosis: Review on aetiology and pathogenesis. Oral Oncol. 2006;42:561-568.

[45]. Shieh T.M., Tu H.F., Ku T.H., Chang S.S., Chang K.W., Liu C.J. Association between lysyl oxidase polymorphisms and oral submucous fibrosis in older male areca chewers. J. Oral Pathol. Med. 2009;38:109-113.

[46]. Liu C.M., Liao Y.W., Hsieh P.L., Yu C.H., Chueh P.J., Lin T., Yang P.Y., Yu C.C., Chou M.Y. miR-1246 as a therapeutic target in oral submucosa fibrosis pathogenesis. J. Formos. Med. Assoc. 2019;118:1093-1098.

[47]. Angadi P.V., Rekha K.P. Oral submucous fibrosis: A clinicopathologic review of 205 cases in Indians. Oral Maxillofac. Surg. 2011;15:1519.

[48]. Angadi P.V., Rao S.S. Areca nut in pathogenesis of oral submucous fibrosis: Revisited. Oral Maxillofac. Surg. 2011;15:1-9.

[49]. Chang M.C., Lin L.D., Wu H.L., Ho Y.S., Hsien H.C., Wang T.M., Jeng P.Y., Cheng R.H., Hahn L.J., Jeng J.H. Areca nut-induced buccal mucosa fibroblast contraction and its signaling: $A$ potential role in oral submucous fibrosis-A precancer condition. Carcinogenesis. 2013;34:1096-1104.

[50]. Prabhu R.V., Prabhu V., Chatra L., Shenai P., Suvarna N., Dandekeri S. Areca nut and its role in oral submucous fibrosis. J. Clin. Exp. Dent. 2014;6:e569-e575.]

[51]. Anila Namboodiripad P.C. Cystatin C: Its role in pathogenesis of OSMF. J. Oral Biol. Craniofac. Res. 2014;4:42-46.

[52]. Arakeri G., Rai K.K., Hunasgi S., Merkx M.A.W., Gao S., Brennan P.A. Oral submucous fibrosis: An update on current theories of pathogenesis. J. Oral Pathol. Med. 2017;46:406412.

[53]. Tilakaratne W.M., Klinikowski M.F., Saku T., Peters T.J., Warnakulasuriya S. Oral submucous fibrosis: Review on aetiology and pathogenesis. Oral Oncol. 2006;42:561-568.

[54]. Angadi P.V., Rao S.S. Areca nut in pathogenesis of oral submucous fibrosis: Revisited. Oral Maxillofac. Surg. 2011;15:1-9. 
[55]. Arakeri G., Brennan P.A. Oral submucous fibrosis: An overview of the aetiology, pathogenesis, classification, and principles of management. Br. J. Oral Maxillofac. Surg. 2013;51:587-593.

[56]. Arakeri G., Rai K.K., Hunasgi S., Merkx M.A.W., Gao S., Brennan P.A. Oral submucous fibrosis: An update on current theories of pathogenesis. J. Oral Pathol. Med. 2017;46:406412.

[57]. Angadi P.V., Rao S.S. Areca nut in pathogenesis of oral submucous fibrosis: Revisited. Oral Maxillofac. Surg. 2011;15:1-9.

[58]. Aziz S.R. Oral submucous fibrosis: Case report and review of diagnosis and treatment. J. Oral Maxillofac. Surg. 2008;66:2386-2389.

[59]. Angadi P.V., Rao S.S. Areca nut in pathogenesis of oral submucous fibrosis: Revisited. Oral Maxillofac. Surg. 2011;15:1-9.

[60]. Arakeri G., Brennan P.A. Oral submucous fibrosis: An overview of the aetiology, pathogenesis, classification, and principles of management. Br. J. Oral Maxillofac. Surg. 2013;51:587-593.

[61]. Shieh D.H., Chiang L.C., Shieh T.Y. Augmented mRNA expression of tissue inhibitor of metalloproteinase-1 in buccal mucosal fibroblasts by arecoline and safrole as a possible pathogenesis for oral submucous fibrosis. Oral Oncol. 2003;39:728-735.

[62]. Pant I., Kumar N., Khan I., Rao S.G., Kondaiah P. Role of areca Nut induced TGF-beta and epithelial-mesenchymal interaction in the pathogenesis of oral submucous fibrosis. PLoS ONE. 2015;10:e0129252.

[63]. Lin C.Y., Hsieh P.L., Liao Y.W., Peng C.Y., Yu C.C., Lu M.Y. Arctigenin reduces myofibroblast activities in oral submucous fibrosis by LINC00974 inhibition. Int. J. Mol. Sci. 2019;20:1328.
[64]. Yeh M.C., Chen K.K., Chiang M.H., Chen C.H., Chen P.H., Lee H.E., Wang Y.H. Low-power laser irradiation inhibits arecoline-induced fibrosis: An in vitro study. Int. J. Oral Sci. 2017;9:38-42.

[65]. Angadi P.V., Rao S.S. Areca nut in pathogenesis of oral submucous fibrosis: Revisited. Oral Maxillofac. Surg. 2011;15:1-9.

[66]. Lin C.Y., Hsieh P.L., Liao Y.W., Peng C.Y., Yu C.C., Lu M.Y. Arctigenin reduces myofibroblast activities in oral submucous fibrosis by LINC00974 inhibition. Int. J. Mol. Sci. 2019;20:1328.

[67]. Arakeri G., Rai K.K., Hunasgi S., Merkx M.A.W., Gao S., Brennan P.A. Oral submucous fibrosis: An update on current theories of pathogenesis. J. Oral Pathol. Med. 2017;46:406412.

[68]. Angadi P.V., Rao S.S. Areca nut in pathogenesis of oral submucous fibrosis: Revisited. Oral Maxillofac. Surg. 2011;15:1-9.

[69]. Arakeri G., Rai K.K., Hunasgi S., Merkx M.A.W., Gao S., Brennan P.A. Oral submucous fibrosis: An update on current theories of pathogenesis. J. Oral Pathol. Med. 2017;46:406412.

[70]. Haque M.F., Harris M., Meghji S., Barrett A.W. Immunolocalization of cytokines and growth factors in oral submucous fibrosis. Cytokine. 1998;10:713-719.

[71]. Jeng J.H., Ho Y.S., Chan C.P., Wang Y.J., Hahn L.J., Lei D., Hsu C.C., Chang M.C. Areca nut extract up-regulates prostaglandin production, cyclooxygenase-2 mRNA and protein expression of human oral keratinocytes. Carcinogenesis. 2000;21:1365-1370.

[72]. Jeng J.H., Wang Y.J., Chiang B.L., Lee P.H., Chan C.P., Ho Y.S., Wang T.M., Lee J.J., Hahn L.J., Chang M.C. Roles of keratinocyte inflammation in oral cancer: Regulating the prostaglandin E2, interleukin-6 and TNF-alpha 
production of oral epithelial cells by areca nut extract and arecoline. Carcinogenesis. 2003;24:1301-1315.

[73]. Aziz S.R. Oral submucous fibrosis: Case report and review of diagnosis and treatment. J. Oral Maxillofac. Surg. 2008;66:2386-2389.

[74]. Auluck A, Rosin MP, Zhang L, Sumanth KN. Oral submucous fibrosis, a clinically benign but potentially malignant disease: Report of 3 cases and review of the literature. J Can Dent Assoc 2008;74:735-40.

[75]. Jayanthi V, Probert CS, Sher KS, Mayberry JF. Oral submucosal fibrosis-- A preventable disease. Gut 1992;33:4-6.

[76]. Chitturi RT, Kumar VA, Naik P, Kattimani V. Oral submucous fibrosis- An Indian perspective. Research 2014;1:702.

[77]. Gupta L, Gupta N, Punn K, Chandel S. Oral submucous fibrosis: A clinical note. Asian J Oral Health Allied Sci 2011;1:229.

[78]. Auluck A, Rosin MP, Zhang L, Sumanth KN. Oral submucous fibrosis, a clinically benign but potentially malignant disease: Report of 3 cases and review of the literature. J Can Dent Assoc 2008;74:735-40.

[79]. Wahi PN, Kapur VLLuthra UK, Srivastava MC. Submucous fibrosis of the oral cavity. 2. Studies on epidemiology. Bull World Health Organ 1966;35:793-9

[80]. Pindborg JJ, Sirsat SM. Oral submucous fibrosis. Oral Surg Oral Med Oral Pathol 1966;22:76479.

[81]. Lai DR, Chen HR, Lin LM, Huang YL, Tsai CC. Clinical evaluation of different treatment methods for oral submucous fibrosis. A 10-year experience with 150 cases. J Oral Pathol Med 1995;24:402-6.

[82]. Rao V, Raju PR. Treatment of SMF with cortisone. Indian J Otolaryngol 1954;6:81-3.
[83]. Desa JV. Submucous fibrosis of the palate and cheek. Ann Otol Rhinol Laryngol 1957;66:114359.

[84]. George AT. Submucous fibrosis of the palate and buccal mucosa membrane. J Indian Med Assoc 1958;31:489-90.

[85]. Hamner JE 3rd, Looney DD, Chused TM. Submucous fibrosis. Oral Surg Oral Med Oral Pathol 1974;37:412-21.

[86]. Kakar PK, Puri RK, Venkatachalam VP. Oral submucous fibrosis- Treatment with hyalase. J Laryngol Otol 1985;99:57-9.

[87]. Singh M, Niranjan HS, Mehrotra R, Sharma D, Gupta SC. Efficacy of hydrocortisone acetate/hyaluronidase vs triamcinolone acetonide/hyaluronidase in the treatment of oral submucous fibrosis. Indian J Med Res 2010;131:665-9.

[88]. Rajendran R, Rani V, Shaikh S. Pentoxifylline therapy: A new adjunct in the treatment of oral submucous fibrosis. Indian J Dent Res 2006;17:190.

\section{Cite this article as :}

Shraddha Awasthi, Ausaf Ahmad, Anand Narain Srivastava, "Regulation of Collagen Synthesis in Tobacco/Pan-Masala Induced Oral Sub-Mucosal Fibrosis and Diagnostic Approach - Review Article", International Journal of Scientific Research in Science and Technology (IJSRST), Online ISSN : 2395-602X, Print ISSN : 2395-6011, Volume 8 Issue 1, pp. 134-143, January-February 2021. Available at doi $\quad$ : https://doi.org/10.32628/IJSRST218114

Journal URL : http://ijsrst.com/IJSRST218114 